\title{
BMJ Open Distribution and determinants of hospital efficiency and relative productivity in county-level hospitals in rural China: an observational study
}

\author{
Jing Zhong, ${ }^{1}$ Wei Wang (D) , ${ }^{1}$ Hongxi Wang, ${ }^{2}$ Jingjing Huang (D) , ${ }^{3} \mathrm{Tao} \mathrm{Li}^{1}$ \\ Jingjing Chen, ${ }^{4}$ Wan Chen, ${ }^{4}$ Jin Yuan (D) , ${ }^{1}$ Weirong Chen ${ }^{1}$
}

To cite: Zhong J, Wang W, Wang $\mathrm{H}$, et al. Distribution and determinants of hospital efficiency and relative productivity in county-level hospitals in rural China: an observational study. BMJ Open 2021;11:e042326. doi:10.1136/ bmjopen-2020-042326

- Prepublication history for this paper is available online. To view these files, please visit the journal online (http://dx.doi. org/10.1136/bmjopen-2020042326).

JZ, WW and HW contributed equally.

Received 02 July 2020 Accepted 17 April 2021

Check for updates

(C) Author(s) (or their employer(s)) 2021. Re-use permitted under CC BY-NC. No commercial re-use. See rights and permissions. Published by BMJ.

For numbered affiliations see end of article.

\section{Correspondence to}

Dr Jin Yuan;

yuanjincornea@126.com and

Professor Weirong Chen;

chenwrq@aliyun.com

\section{ABSTRACT}

Background Cataract surgery is very important to prevent blindness, but its productivity and efficiency in China are unknown. Our study aimed to evaluate the geographical distribution of cataract surgeons and prospectively identify the factors associated with the increased productivity in cataract surgery and efficiency in outpatient ophthalmic services in rural Chinese hospitals.

Methods Data were prospectively collated from various hospital datasets and the census registered by the geographical unit county. Prior to mapping, the geographical location data of counties were crosslinked with the equivalent ophthalmologist and service output data to create categories and map multiple data attributes. Descriptive statistical analyses were performed to characterise the data stratified by county. Linear regression analyses were used to explore the factors associated with the increased productivity/efficiency. Results The ophthalmologists, surgical productivity of ophthalmologists and outpatient efficacy of ophthalmologists significantly varied across counties. During the period between 2016 and 2018, the median (IQR) change in surgical productivity of and outpatient efficacy of ophthalmologists were 31.627 ( -3.33 to $29.94)$ and 118.08 (-132.30 to 740.89$)$. In the simple regression analysis for predictors of a high productivity change, only the increased number of phaco machine had statistical significance $(p=0.003)$. In addition, only the gross domestic product per capita in 2016 was associated with an increased improvement in efficiency of outpatient services $(p=0.008)$

Conclusions This study demonstrated that the ophthalmologist productivity and the efficiency of outpatient services were unequally geographically distributed, and their predictors were identified. Further studies to elucidate the extent of the problem and improve the health service delivery models are required.

\section{INTRODUCTION}

China has the largest number of people with blindness, and half of the cases are due to cataracts. ${ }^{1}$ The number of operable cataracts can be at least four times the number of blind people. ${ }^{1}$ The only effective treatment for cataract is surgery. ${ }^{2}$ The principal source of eye
Strengths and limitations of this study

- This study included all representative county hospitals in Guangdong Province, China.

- The data directly come from a standardised government monitoring database in this study.

- The study only included hospitals in rural areas of one province in China.

- The observation time span is only 2 years, and longterm changes must be verified.

- Patient-level information may further increase the effectiveness of this study.

care for rural dwellers in China is county-level facilities, of which there are approximately 2400 , with each covering an average population of approximately $500000 .{ }^{34}$ County-level hospitals with eye services accounted for $51 \%$ of the total number of hospitals in $2015 .^{3}{ }^{4}$ There are approximately 30000 eye doctors in China, but fewer than half can independently perform cataract operations, and those that can are mostly based in large cities. ${ }^{5}$ These differences in health service capacities indicate substantial gaps between the patients' needs and the current service provisions, especially at the county level, which can cause urban/rural health inequalities.

High-quality care, including effective, patient-centred, timely, efficient and equitable ophthalmic services, is an important factor to eliminate blindness in counties. ${ }^{7}$ In September 2015, the Ministry of Health $(\mathrm{MOH})$ of China issued the 70th version of 'Guidelines on how to promote the tiered medical service scheme', which encourages counties 'to keep $90 \%$ of patients in the county, with capacity to provide services for serious diseases, including cataracts'. ${ }^{8}$ Therefore, the service capacity at countylevel hospitals must be greatly improved to satisfy this requirement. However, the lack 


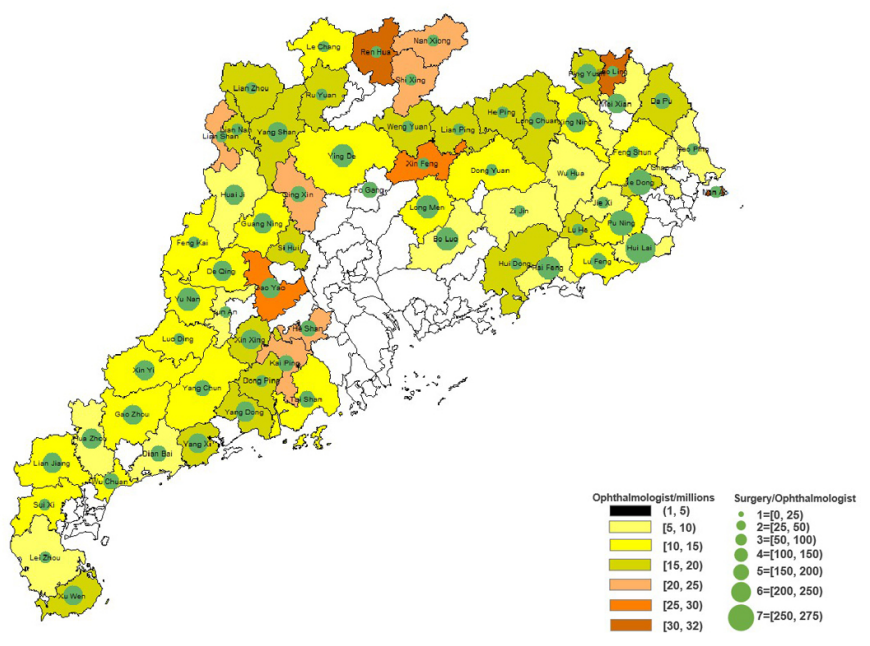

Figure 1 Geographical distribution of the cataract surgery productivity in 2016.

of surgical training, lack of surgical quality and patient safety monitoring, poor patient experiences, lack of outpatient options and lack of transparency in patient outcomes have been reported, which causes mistrust between doctors and patients. ${ }^{9-12}$

To achieve the objective by MOH of China, the Guangdong Provincial Government initiated the people's livelihood projects including the Enhancement of the Capacity of the County-level Hospital Project in 2016, which is a quantitative and qualitative study of the efficacy and predictors of a 2-year increase in ophthalmic capacity in more than 60 county/prefecture-level hospitals in Guangdong Province, China. This report aimed to evaluate the geographical distribution of the productivity of cataract surgeons and efficiency of outpatient ophthalmic services and identify the factors that predicted the increases in these parameters over 2 years.

\section{METHODS}

This study was performed between January 2016 and December 2018. Oral informed consent was obtained from all participating administrators and ophthalmologists. The tenets of the Declaration of Helsinki were followed throughout.

\section{Participant hospitals and ophthalmic service data}

Guangdong is a province at the southernmost tip of mainland of China, adjacent to Hong Kong and Macau; it has 21 prefecture-level divisions encompassing 119

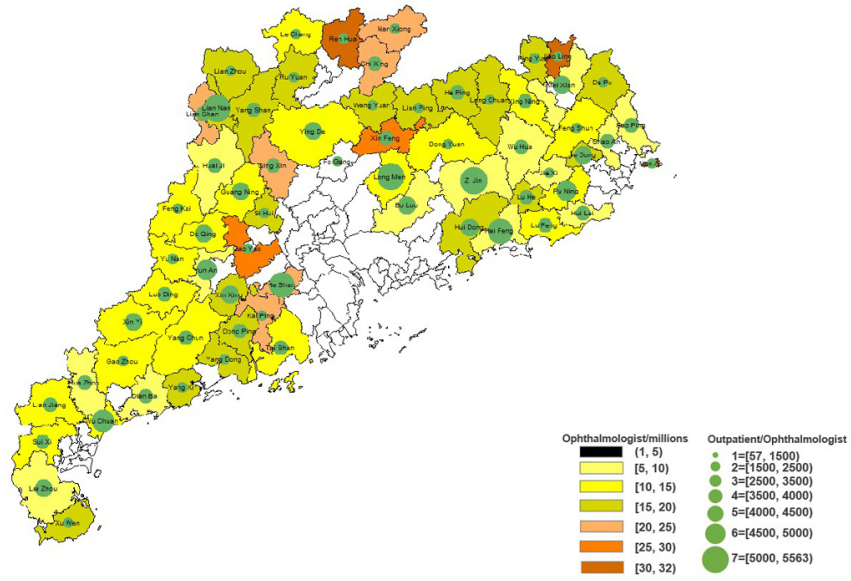

Figure 2 Geographical distribution of the ophthalmic service efficacy in 2016.

county-level divisions. ${ }^{13}$ It topped the total gross domestic product (GDP) rankings among all provincial-level divisions, which makes its economy approximately equivalent to that of Australia. Public hospitals in distinct areas of Guangdong were selected to represent the range of available care in rural China. The annual cataract surgical volume was recorded at the time of ascertainment of baseline data and 24 months later. These data were directly obtained from Guangdong Provincial Government Health Monitoring Database, which provided the demographic and professional information, including the population of the catchment area (typically a county in this case), infrastructure, annual outpatient clinical volume in the ophthalmology department, per capita GDP and total annual cataract surgical output for the hospital catchment area.

\section{Enhancement of the Capacity of the County-level Hospital Project}

In 2016, the Guangdong Provincial Government launched the Enhancement of the Capacity of Countylevel Hospital Programme to improve the capacity of ophthalmic services at 65 county hospitals in Guangdong Province, which represent the basic level of Guangdong Province and socioeconomic level of non-urban areas of China. China has now achieved a $98 \%$ coverage rate of basic health insurance for both rural and urban populations nationwide. ${ }^{14}$ In Guangdong Province, the medical cost of cataract surgery was $100 \%$ covered by the government insurance for all residents in the area. Zhongshan Ophthalmic Center (ZOC), which is the largest ophthalmic

Table 1 Basic characteristics of the included hospitals in Guangdong (65 counties)

\begin{tabular}{lrrrr}
\hline Features of cities/county & Average & SD & Maximum & \multicolumn{1}{c}{ Minimum } \\
\hline Population & 3496827 & 1968515 & 7946200 & 1026504 \\
Ophthalmologists & 48 & 40 & 167 & 12 \\
Cataract surgery rate & 2561 & 1782 & 7169 & 140 \\
Outpatient visit rate & 136070 & 120687 & 441732 & 14760 \\
\hline
\end{tabular}


Table 2 Cataract surgery productivity stratified by the county-level and hospital factors during 2016-2018

\begin{tabular}{|c|c|c|c|c|}
\hline \multirow[b]{2}{*}{ Characteristics } & \multicolumn{2}{|l|}{ Productivity } & \multirow[b]{2}{*}{ Absolute difference } & \multirow[b]{2}{*}{ P value } \\
\hline & Year 2016 & Year 2018 & & \\
\hline \multicolumn{5}{|c|}{ Region of hospital location } \\
\hline Pearl River Delta & $63.57 \pm 38.57$ & $53.93 \pm 19.54$ & $-9.64 \pm 27.68$ & 0.489 \\
\hline Eastern Guangdong & $70.68 \pm 19.95$ & $70.55 \pm 74.57$ & $-0.12 \pm 76.13$ & 0.996 \\
\hline Western Guangdong & $42.84 \pm 38.20$ & $104.83 \pm 81.94$ & $61.99 \pm 91.91$ & 0.054 \\
\hline Northern Guangdong & $30.36 \pm 28.16$ & $50.55 \pm 22.00$ & $20.18 \pm 22.71$ & 0.107 \\
\hline
\end{tabular}

Economic levels (GDP per

capita, RMB)

\begin{tabular}{|c|c|c|c|c|}
\hline Highest quartile & $157.45 \pm 102.10$ & $106.11 \pm 62.88$ & $28.96 \pm 94.68$ & 0.191 \\
\hline The third quartile & $143.89 \pm 90.65$ & $182.09 \pm 143.01$ & $38.2 \pm 105.52$ & 0.507 \\
\hline The second quartile & $126.31 \pm 108.29$ & $216.42 \pm 175.79$ & $90.12 \pm 197.81$ & 0.183 \\
\hline \multicolumn{5}{|l|}{ Resident population } \\
\hline Highest quartile & $70.47 \pm 34.90$ & $64.46 \pm 64.41$ & $-6.01 \pm 65.08$ & 0.788 \\
\hline Second quartile & $49.58 \pm 35.08$ & $53.49 \pm 39.14$ & $3.910 \pm 49.28$ & 0.807 \\
\hline Lowest quartile & $43.69 \pm 41.73$ & $59.39 \pm 33.86$ & $15.70 \pm 51.39$ & 0.450 \\
\hline \multicolumn{5}{|l|}{ Department of ophthalmology } \\
\hline $\begin{array}{l}\text { Incorporated to ENT } \\
\text { department }\end{array}$ & $43.82 \pm 33.16$ & $70.53 \pm 63.34$ & $26.71 \pm 69.60$ & 0.057 \\
\hline$>5-\leq 10$ & $46.46 \pm 43.37$ & $78.86 \pm 80.84$ & $32.40 \pm 42.88$ & 0.366 \\
\hline$>3-\leq 5$ & $99.33 \pm 161.70$ & $149.75 \pm 165.25$ & $50.42 \pm 151.25$ & 0.546 \\
\hline 3 & $84.94 \pm 59.06$ & $79.19 \pm 75.911$ & $-5.76 \pm 72.95$ & 0.852 \\
\hline $0-2$ & $92.24 \pm 99.45$ & $63.31 \pm 31.14$ & $-28.93 \pm 99.77$ & 0.326 \\
\hline
\end{tabular}

Change in hospital beds during

the project

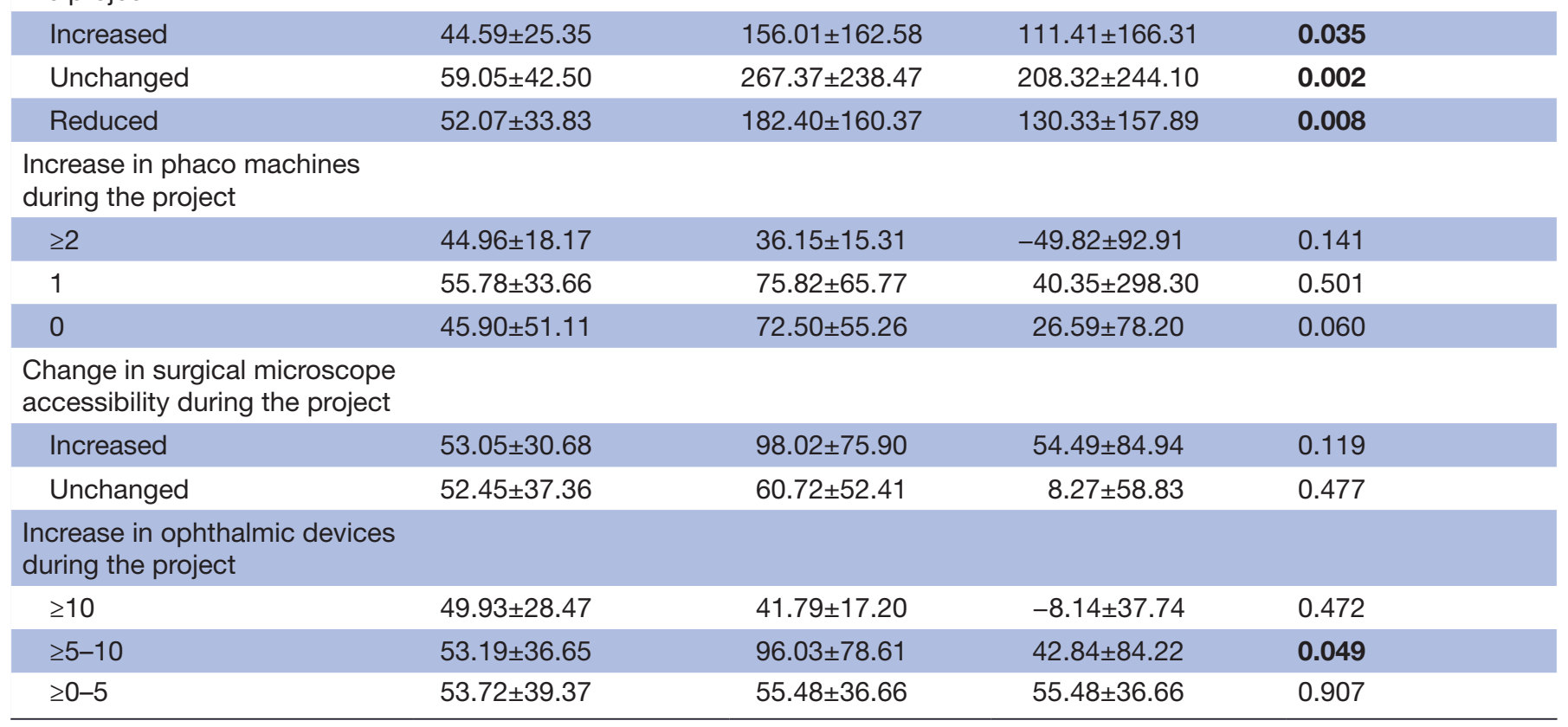


Table 2 Continued

\begin{tabular}{lllll} 
& \multicolumn{2}{l}{ Productivity } & & \\
\cline { 2 - 3 } Characteristics & Year 2016 & Year 2018 & Absolute difference & P value* \\
\hline $\begin{array}{l}\text { Change in nurse-to-doctor ratio } \\
\text { during the project }\end{array}$ & & & & \\
\multicolumn{1}{l}{$\begin{array}{l}\text { Increased } \\
\text { Unchanged }\end{array}$} & $106.24 \pm 90.83$ & $328.85 \pm 417.33$ & $222.61 \pm 447.46$ & 0.190 \\
$\quad$ Reduced & $176.74 \pm 128.09$ & $247.79 \pm 188.22$ & $71.044 \pm 214.14$ & 0.207 \\
\hline
\end{tabular}

The bold indicates the statistical significance.

*Paired t-test.

†bold indicates the statistical significance

ENT, ear, nose and throat; GDP, gross domestic product; RMB, renminbi.

hospital, was responsible for managing this project. The training model consisted of four components: (1) an assessment of hospitals in terms of equipment, facilities, staff, surgeon experience and administrative support; (2) education for trainees regarding screening for cataracts, preoperative assessment, cataract surgery and postoperative management; (3) 2-month didactic and wet lab training on the principles of cataract surgery and refractive examination at ZOC; (4) hands-on training by ZOC trainers during supervised surgeries at the county hospitals. All the hospitals received the same and standardised evaluation and training. The overall aim of this proposed programme was to improve the surgical productivity of ophthalmologists and capacity of ophthalmic services in county hospitals in China.

\section{Statisticalanalyses}

The density of ophthalmologists was defined as the number of ophthalmologists per million people. The cataract surgical rate (CSR, measured in cases per million population per year) for each hospital was calculated by dividing the annual total cataract surgical volume of each hospital from the surgical records by the catchment area population. The outpatient visit rate for each hospital was calculated by dividing the annual total outpatients who attended each hospital from the electronic health record (EHR) by the catchment area population. The surgical productivity of the ophthalmologists was defined as the number of cataract surgeries per year per ophthalmologist. ${ }^{15} 16$ The efficiency of outpatient services was defined as the number of outpatient visits per ophthalmologist. ${ }^{1718}$ The principal study outcome was the 2-year change in productivity and efficiency in each hospital, and the pure arithmetic increase in number of surgeries was considered an increase in productivity.

The baseline hospital, patient and surgeon characteristics were described as the means (SDs) if they were continuous variables with a normal distribution, medians (IQRs) if they were continuous variables with a nonnormal distribution, and frequencies (percentages) if they were categorical variables. The 2-year changes with each outcome were calculated for each hospital, and the means and medians (IQRs) were reported. Simple linear regression models were used to investigate the effects of the macro-level indicators on the baseline productivity/ efficiency and 2-year changes in productivity/efficiency for hospitals. All variables with a $p$ value of $<0.05$ in the simple regression models of the primary and secondary outcomes were included in the multiple regression analysis. All analyses were performed using the Stata V.14.0 software (StataCorp, College Station, Texas, USA).

\section{Patient and public involvement}

Patients were not involved in the preparation of the study protocol.

\section{RESULTS}

Table 1 shows the demographic and professional information and the socioeconomic factors in the catchment areas of the participating hospitals. In total, 65 hospitals were included in the study. The median size of the patient catchment area was 530000 (IQR, 380000-850000) people, the median CSR for areas surrounding the hospitals was 643 (IQR, 356-1005) cases per million per year, and the facilities performed a median of 191 cataract surgeries and examined 9484 outpatients per year.

Figure 1 shows the geographical distribution of the surgical productivity of ophthalmologists. The ophthalmologist density and surgical productivity of the ophthalmologists varied across counties. Figure 2 presents the geographical distribution of the efficiency of outpatient services. The baseline efficiency of outpatient services was disproportionately distributed with higher productivity in area with higher GDP per capita.

Table 2 shows the 2-year changes in surgical productivity during the period stratified by the macro-indicators. Figure 3 shows the 2-year change in surgical productivity of ophthalmologists at 56 participating hospitals in rank order. The median (IQR) change was 31.627 (-3.33 to $29.94)$, and the range was -110.46 to 829.88 . Table 3 shows the per cent changes in outpatient service efficacy during the period stratified by the macro-indicators. Figure 4 shows the 2-year per cent change in outpatient 


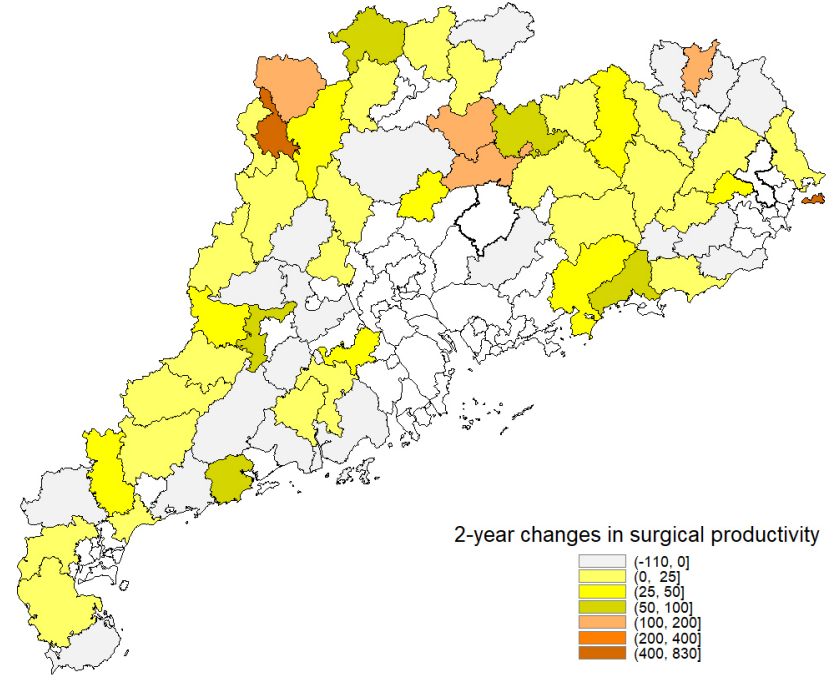

Figure 3 Two-year change in surgical productivity of the ophthalmologists.

service efficacy in rank order. The median (IQR) change was 118.08 ( -132.30 to 740.89 ), and the range was from -1932.93 to 7874.02 .

In the simple regression analysis for predictors of a high productivity change, only the increased number of phaco machine had statistical significance $(\mathrm{p}=0.003)$ (table 4). Using similar models, predictors of high improvement in the efficiency of outpatient services in the simple regression models included the region of the hospital, GDP per capita in 2016 and number of ophthalmologists (all $\mathrm{p}<0.05$, table 5). In multiple models, only the GDP per capita in 2016 was associated with an increased improvement in efficiency of outpatient services $(p=0.008)$.

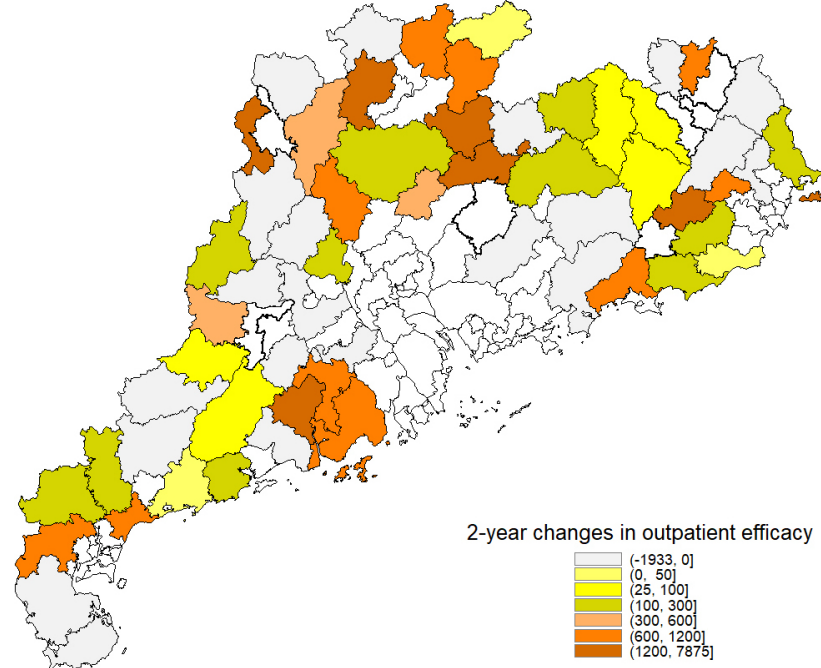

Figure 4 Two-year change in outpatient service efficacy of the ophthalmologists.

\section{DISCUSSION}

After receiving support and training, the annual surgical output generally increased in these facilities at a median rate of 118.08 over 2 years. Our findings indicate that all factors that predicted our main outcome, which is the 2-year change in surgical productivity, were under the direct control of the hospitals. The infrastructure, that is, the number of phaco machines, was the only predictor of the ophthalmologist productivity, while the GDP per capita was the only predictor of the efficiency of outpatient services. Our results highlight the importance of increasing hardware for surgical services in addition to the capacity to supply them in this setting.

The distribution of the CSR and ophthalmologist density varied across counties, which is consistent with previous studies. ${ }^{19-21}$ The CSR is a key indicator to monitor eye care services; it represents the number of cataract

Table 3 Ophthalmic service efficacy stratified by the county-level and hospital factors during 2016-2018

\begin{tabular}{|c|c|c|c|c|}
\hline \multirow[b]{2}{*}{ Characteristics } & \multicolumn{2}{|c|}{ Efficiency of outpatient service } & \multirow[b]{2}{*}{ Absolute difference } & \multirow[b]{2}{*}{ P value* } \\
\hline & Year 2018 & Year 2016 & & \\
\hline Number of doctors & $7.66 \pm 0.53$ & $6.68 \pm 0.44$ & $0.98 \pm 0.22$ & $<0.001$ \\
\hline Number of optometrists & $0.87 \pm 0.17$ & $0.73 \pm 0.16$ & $0.10 \pm 0.79$ & 0.162 \\
\hline Number of phaco machines & $1.07 \pm 0.09$ & $0.80 \pm 0.10$ & $0.06 \pm 0.45$ & $<0.001$ \\
\hline Number of surgeries & $418.26 \pm 56.76$ & $318.49 \pm 49.12$ & $22.47 \pm 181.16$ & $<0.001$ \\
\hline Number of yearly outpatient visits & $14522.1 \pm 1615.3$ & $12195.9 \pm 1239.0$ & $530.85 \pm 4279.84$ & $<0.001$ \\
\hline Number of phaco machines per surgeon & $52.46 \pm 6.17$ & $44.76 \pm 6.39$ & $3.95 \pm 31.86$ & 0.055 \\
\hline Number of outpatient visits per doctor & $1986.9 \pm 145.8$ & $1978.2 \pm 154.3$ & $78.48 \pm 632.74$ & 0.912 \\
\hline Number of phaco surgeries per million population & $93.66 \pm 17.21$ & $57.91 \pm 8.20$ & $17.06 \pm 136.52$ & 0.040 \\
\hline
\end{tabular}

Bold indicates statistical significance.

${ }^{*}$ Paired t-test. 
Table 4 Linear regression analysis of the factors associated with the changes in cataract surgeon productivity during the period between 2016 and 2018

\begin{tabular}{|c|c|c|c|}
\hline Factors & Coefficient & $95 \% \mathrm{Cl}$ & $P$ value \\
\hline \multicolumn{4}{|l|}{ Region of hospital location } \\
\hline Pearl River Delta & Reference & & \\
\hline Eastern Guangdong & 42.08 & -54.74 to -138.91 & 0.388 \\
\hline Western Guangdong & 97.72 & -8.42 to -203.85 & 0.070 \\
\hline Northern Guangdong & 7.39 & -95.65 to -110.42 & 0.886 \\
\hline \multicolumn{4}{|l|}{ Training sessions during the project } \\
\hline $\mathrm{N} \leq 1$ & Reference & & \\
\hline $\mathrm{N}=2$ & -29.6 & -124.61 to -65.39 & 0.535 \\
\hline $\mathrm{N}=3$ & -68.93 & -163.93 to -26.07 & 0.152 \\
\hline Department (independent vs ENT) & -36.4 & -117.05 to -44.24 & 0.370 \\
\hline Change in hospital beds during the project & -0.95 & -4.99 to -3.09 & 0.640 \\
\hline Increase in phaco machines during the project & 111.4 & 38.86 to -183.94 & 0.003 \\
\hline GDP per capita in 2016 & 0.003 & -0.012 to -0.018 & 0.679 \\
\hline Number of ophthalmologists in 2016 & -9.17 & -28.53 to -10.19 & 0.347 \\
\hline Number of nurses in 2016 & -1.09 & -66.38 to -64.20 & 0.973 \\
\hline Number of optometrists in 2016 & -7.67 & -51.27 to -35.93 & 0.726 \\
\hline
\end{tabular}

Productivity of cataract surgeons=number of cataract surgeries per million population per ophthalmologist.

Bold indicates statistical significance.

ENT, ear, nose and throat; GDP, gross domestic product.

extractions performed per million population per year at a given location. ${ }^{21}$ To reduce visual impairment due to cataracts, the CSR must be greater than the incidence rate of cataracts. It was reported that the highest concentrations of ophthalmologists were in regions with higher GDPs and consequently higher CSRs in Brazil. ${ }^{22}$ The

Table 5 Linear regression analysis of the factors associated with the increased efficiency of outpatient visits

\begin{tabular}{llll}
\hline Factors & Coefficient & $\mathbf{9 5 \%} \mathbf{C l}$ & P value \\
\hline $\begin{array}{l}\text { Region of hospital location } \\
\text { Pearl River Delta }\end{array}$ & Reference & & \\
$\quad$ Eastern Guangdong & 607.1 & -323.8 to -1538.1 & 0.197 \\
$\quad$ Western Guangdong & 1083.1 & 62.5 to -2103.7 & $\mathbf{0 . 0 3 8}$ \\
$\quad$ Northern Guangdong & 292.4 & 695.0 to -1279.8 & 0.555 \\
\hline $\begin{array}{l}\text { Training sessions during the project } \\
\mathrm{N} \leq 1\end{array}$ & Reference & & \\
$\mathrm{N}=2$ & 314.5 & -621.2 to -1250.3 & 0.504 \\
$\quad \mathrm{~N}=3$ & -249.3 & -1191.0 to -692.5 & 0.598 \\
\hline Department (independent vs ENT) & -181 & -959.3 to -597.2 & 0.643 \\
\hline Change in hospital beds during the project & -6.13 & -44.6 to -32.4 & 0.751 \\
\hline Increase in phaco machines during the project & 345 & -429.4 to -1119.4 & 0.376 \\
GDP per capita in 2016 & 0.193 & 0.053 to -0.333 & $\mathbf{0 . 0 0 8}$ \\
\hline Number of ophthalmologists in 2016 & -290.41 & -467.34 to -113.4 & $\mathbf{0 . 0 0 2}$ \\
\hline Number of nurses in 2016 & -183.1 & -804.6 to -438.3 & 0.558 \\
\hline Number of optometrists in 2016 & 45.9 & -373.0 to -464.8 & 0.827 \\
\hline
\end{tabular}

Efficiency of outpatient visits=number of outpatients per ophthalmologist.

Bold indicates statistical significance.

ENT, ear, nose and throat; GDP, gross domestic product. 
reality is that the GDP most likely correlates with poor access to services and not necessarily with the paying capacity. ${ }^{21}$

Due to the low number of ophthalmologists, a high number of patients do not receive eye care services, and the ophthalmologists are overworked. ${ }^{5}$ This study shows that the shortages and uneven distributions of ophthalmologists greatly affect the areas with poor socioeconomic status. As ageing progresses, the number of incidences of age-related eye diseases such as agerelated macular degeneration and cataracts increases, and the demand for ophthalmologists increases accordingly. ${ }^{5}$ The density of ophthalmologists varied with socioeconomic development from 9 per million people in developing counties to 79 per million people in developed counties. ${ }^{5}$ A study of the Singaporean population showed that the ageing population ultimately doubled the number of patients with eye diseases, which increased the demand for eye care in public health institutions. ${ }^{23}$ In Canada, workforce planning, resource allocation and data collection are very important tasks, but these tasks are insufficient to address the shortage of ophthalmologists. ${ }^{24-27}$ Therefore, it is necessary to increase the number of ophthalmologists and improve the problem of uneven distribution.

The productivity of ophthalmologists and efficiency of ophthalmic services were also unevenly distributed across counties in Guangdong Province. Since cataracts remain the most important cause of blindness worldwide, it is important to increase the number of cataract surgeons. ${ }^{28}$ To cope with the severe shortage of cataract surgeons, some African countries have adopted a task-shifting strategy to train nurses and physicians in cataract surgery. ${ }^{29-31}$ For countries that cannot quickly increase the number of ophthalmologists, increasing the surgical productivity of ophthalmologists can improve the efficiency of blindness prevention. ${ }^{15}$ The Global Action Plan 2006-2011 estimates that the worldwide goal of ophthalmic human resources is $\geq 4$ ophthalmologists per million population based on 2-3 units/hour per cataract physician. ${ }^{32}$ If the surgical productivity of each ophthalmologist increases, the target demand for human resources will decrease.

Few studies have investigated factors that potentially affect the cataract surgery output in rural hospitals. ${ }^{15} 16$ In a cross-sectional study of hospitals in East Africa, Courtright $e t a l^{15}$ found that increased productivity was associated with having two or more cataract surgery equipment sets, a well-functioning operating microscope, three or more nursing support staff, and the ability to transport patients. Eliah $e t a \hat{l}^{1}$ reported that high-quality training was necessary but not sufficient to improve the cataract surgery rates to satisfy the population needs and maintain surgical skills. Supporting institutions and staff, functioning equipment and programmes to recruit and transport patients are essential for improving the productivity of cataract surgeons. ${ }^{15-1733}$ This study indicates that the strategies for training, supporting and supervising cataract surgeons in China must be revised to create conditions amenable to increased productivity.
Rural hospitals are most likely to benefit from an investment in phaco machines.

The strengths of the current study are its prospective design and the enrolment of many hospitals in Guangdong Province. The collected data covered most of the macrolevel factors that were posited as important in driving the demand for ophthalmic services, and they were used as much as possible. However, this study has limitations. First, all hospitals were in Guangdong Province, which is a relatively high-income province in China. These hospitals were not identified using a randomised sampling strategy; thus, care must be taken in generalising these results to over 2000 existing county hospitals in China. Second, patient-level factors were not obtained; however, it was not practical for us to record exhaustive information on the patients who actually presented to the eye departments for care. Such information might have improved our models, although patient factors generally are not under the control of the facilities. Third, only county-level data were available, which increased the risk of ecological fallacy. However, the ecological analyses inform us about forces that act on the entire populations. Fourth, we only included public hospitals in Guangdong Province, but the vast majority of patients in China are treated in public hospitals and few private hospitals, so we believe that it will not greatly affect our conclusion. Fifth, the information on the populations living in the hospital catchment areas was limited, such as the data for transport networks and distance to the hospital were unavailable. Though it was reported that the driving time to the nearest optometrist/ophthalmologist may affect the eye access in the USA, ${ }^{34-36}$ transportation factors were not considered to be the important barriers for cataract surgery in southern China. ${ }^{37}$ Future incorporation of geographical information systems mapping could help to clarify the role of these factors. ${ }^{38}$ Finally, many factors related to the ophthalmologist productivity and efficiency of outpatient services were not considered. For example, the Lean Six Sigma process has been reported to yield significant improvements in healthcare. ${ }^{18}$ EHRs and scheduling templates can improve the clinical efficiency and operation. ${ }^{1739}$

\section{CONCLUSIONS}

This study is the first report to map the geographical distribution of surgical productivity and efficiency of outpatient services in rural Chinese hospitals. The infrastructure, that is, the number of phaco machines, and socioeconomic status, that is, GDP per capita potentially contributed to the increasing rural cataract surgical capacity over time. Our conclusions provide a potential guide for government investment to increase the number of surgeries and outpatient services.

\section{Author affiliations}

${ }^{1}$ Zhongshan Ophthalmic Center, Sun Yat-Sen University, Guangzhou, China

${ }^{2}$ Joint Shantou International Eye Center of Shantou University and the Chinese University of Hong Kong, Shantou, Guangdong, China

${ }^{3}$ Glaucoma, Zhongshan Ophthalmic Center, Sun Yat-sen University, Guangzhou, Guangdong, China 
${ }^{4}$ State Key Laboratory of Ophthalmology, Zhongshan Ophthalmic Center, Sun Yatsen University, Guangzhou, Guangdong, China

Contributors JY and WRC had full access to all data in the study and take responsibility for the integrity of the data and accuracy of the data analysis. Study concept and design-JY and WRC. Acquisition, analysis or interpretation of data-JZ, WW, HW, TL, JH, JC and WC. Drafting of the manuscript-JZ and WW. Critical revision of the manuscript for important intellectual content-all authors. Statistical analysis-JZ, WW, HW, TL, JH, JC and WRC. Obtained funding-JY and WRC. Administrative, technical or material support- $\mathrm{TL}, \mathrm{JH}, \mathrm{JC}$ and WC. Study supervision-JZ and WW.

Funding This study was supported by the National Natural Science Foundation of China (81 970778 to WRC), Guangdong Basic and Applied Basic Research Foundation (2020A1515010987 to WRC) and Young Teacher Training Project of Sun Yat-sen University (19ykpy154 to JZ).

Disclaimer The funding organisations had no role in the design or conduct of the study, collection, management, analysis, and interpretation of the data, preparation, review, or approval of the manuscript, or decision to submit the manuscript for publication.

Map disclaimer The depiction of boundaries on the map(s) in this article does not imply the expression of any opinion whatsoever on the part of BMJ (or any member of its group) concerning the legal status of any country, territory, jurisdiction or area or of its authorities. The map(s) are provided without any warranty of any kind, either express or implied.

Competing interests None declared.

Patient and public involvement Patients and/or the public were not involved in the design, or conduct, or reporting, or dissemination plans of this research.

Patient consent for publication Not required.

Ethics approval This study was reviewed by the Zhongshan Ophthalmic Ethical Committee and was determined to be exempt from approval, as this study did not involve human subject research.

Provenance and peer review Not commissioned; externally peer reviewed.

Data availability statement Data are available upon reasonable request.

Open access This is an open access article distributed in accordance with the Creative Commons Attribution Non Commercial (CC BY-NC 4.0) license, which permits others to distribute, remix, adapt, build upon this work non-commercially, and license their derivative works on different terms, provided the original work is properly cited, appropriate credit is given, any changes made indicated, and the use is non-commercial. See: http://creativecommons.org/licenses/by-nc/4.0/.

\section{ORCID iDs}

Wei Wang http://orcid.org/0000-0002-5273-3332

Jingjing Huang http://orcid.org/0000-0002-3009-8681

Jin Yuan http://orcid.org/0000-0001-5756-5414

\section{REFERENCES}

1 Song $\mathrm{P}$, Wang $\mathrm{H}$, Theodoratou $\mathrm{E}$, et al. The National and subnational prevalence of cataract and cataract blindness in China: a systematic review and meta-analysis. J Glob Health 2018;8:10804

2 Liu Y-C, Wilkins M, Kim T, et al. Cataracts. Lancet 2017;390:600-12.

3 Zhao J, Xu X, Ellwein LB, et al. Causes of visual impairment and blindness in the 2006 and 2014 Nine-Province surveys in rural China. Am J Ophthalmol 2019;197:80-7.

4 Zhao J, Xu X, Ellwein LB, et al. Prevalence of vision impairment in older adults in rural China in 2014 and comparisons with the 2006 China Nine-Province survey. Am J Ophthalmol 2018;185:81-93.

5 Resnikoff S, Lansingh VC, Washburn L, et al. Estimated number of ophthalmologists worldwide (international Council of ophthalmology update): will we meet the needs? Br J Ophthalmol 2020;104:588-92.

6 Resnikoff S, Felch W, Gauthier T-M, et al. The number of ophthalmologists in practice and training worldwide: a growing gap despite more than 200,000 practitioners. Br J Ophthalmol 2012;96:783-7.

7 Sommer A, Taylor HR, Ravilla TD, et al. Challenges of ophthalmic care in the developing world. JAMA Ophthalmol 2014;132:640-4.

$8 \mathrm{Xu}$ J, Jian W, Zhu K, et al. Reforming public hospital financing in China: progress and challenges. BMJ 2019;365:14015.
9 Campbell RJ, El-Defrawy SR, Bell CM, et al. Effect of cataract surgery volume constraints on recently graduated ophthalmologists: a population-based cohort study. CMAJ 2017;189:E424-30.

10 Cumberland PM, Rahi JS, UK Biobank Eye and Vision Consortium. Visual function, social position, and health and life chances: the UK Biobank study. JAMA Ophthalmol 2016;134:959-66.

11 Kauh CY, Blachley TS, Lichter PR, et al. Geographic variation in the rate and timing of cataract surgery among US communities. JAMA Ophthalmol 2016;134:267-76.

12 Liu T, Congdon N, Yan X, et al. A randomized, controlled trial of an intervention promoting cataract surgery acceptance in rural China: the Guangzhou uptake of surgery trial (GUSTO). Invest Ophthalmol Vis Sci 2012;53:5271-8.

13 Lu J, du Plessis L, Liu Z, et al. Genomic epidemiology of SARSCoV-2 in Guangdong Province, China. Cell 2020;181:997-1003.

14 Wong TY, Zheng Y, Jonas JB, et al. Prevalence and causes of vision loss in East Asia: 1990-2010. Br J Ophthalmol 2014;98:599-604.

15 Courtright P, Ndegwa L, Msosa J, et al. Use of our existing eye care human resources: assessment of the productivity of cataract surgeons trained in eastern Africa. Arch Ophthalmol 2007;125:684-7.

16 Liu T, Ong EL, Yan X, et al. Factors influencing the success of rural cataract surgery programs in China: the study of hospital administration and relative productivity (sharp). Invest Ophthalmol Vis Sci 2013;54:266-73.

17 Hribar MR, Huang AE, Goldstein IH, et al. Data-Driven scheduling for improving patient efficiency in ophthalmology clinics. Ophthalmology 2019;126:347-54.

18 Ciulla TA, Tatikonda MV, EIMaraghi YA, et al. Lean six sigma techniques to improve ophthalmology clinic efficiency. Retina 2018;38:1688-98.

19 Lou L, Wang J, Xu P, et al. Socioeconomic disparity in global burden of cataract: an analysis for 2013 with time trends since 1990. Am J Ophthalmol 2017:180:91-6.

20 Wang W, Yan W, Müller A, et al. A global view on output and outcomes of cataract surgery with national indices of socioeconomic development. Invest Ophthalmol Vis Sci 2017;58:3669-76.

21 Wang W, Yan W, Fotis K, et al. Cataract surgical rate and socioeconomics: a global study. Invest Ophthalmol Vis Sci 2016;57:5872-81.

22 Carvalho RdeS, Diniz AS, Lacerda FM, et al. Gross domestic product (GDP) per capita and geographical distribution of ophthalmologists in Brazil. Arq Bras Oftalmol 2012;75:407-11.

23 Ansah JP, De Korne D, Bayer S, et al. Future requirements for and supply of ophthalmologists for an aging population in Singapore. Hum Resour Health 2015;13:86.

24 Astle W, Simms C, Anderson L. A workforce in crisis: a case study to expand allied ophthalmic personnel. Can J Ophthalmol 2016;51:288-93.

25 Al Ali A, Hallingham S, Buys YM. Workforce supply of eye care providers in Canada: optometrists, ophthalmologists, and subspecialty ophthalmologists. Can J Ophthalmol 2015;50:422-8.

26 Bellan L, Buske L, Wang S, et al. The landscape of ophthalmologists in Canada: present and future. Can J Ophthalmol 2013;48:160-6.

27 Bellan L, Buske L. Ophthalmology human resource projections: are we heading for a crisis in the next 15 years? Can J Ophthalmol 2007;42:34-8.

28 GBD 2019 Blindness and Vision Impairment Collaborators, Vision Loss Expert Group of the Global Burden of Disease Study. Causes of blindness and vision impairment in 2020 and trends over 30 years, and prevalence of avoidable blindness in relation to vision 2020: the right to sight: an analysis for the global burden of disease study. Lancet Glob Health 2021:9:e144-60.

29 Mwangi N, Zondervan M, Bascaran C. Analysis of an international collaboration for capacity building of human resources for eye care: case study of the college-college vision 2020 link. Hum Resour Health 2017;15:22.

30 Lewallen S, Etya'ale D, Kello AB, et al. Non-Physician cataract surgeons in sub-Saharan Africa: situation analysis. Trop Med Int Health 2012;17:1405-8.

31 Eliah E, Lewallen S, Kalua K, et al. Task shifting for cataract surgery in eastern Africa: productivity and attrition of non-physician cataract surgeons in Kenya, Malawi and Tanzania. Hum Resour Health 2014;12 Suppl 1:S4.

32 World Health organization (who). vision 2020 - the right to sight. global initiative for the elimination of avoidable blindness: action plan 2006-2011, 2012. Available: http://www.who.int/blindness/ Vision2020_report

33 Al Hroub A, Obaid A, Yaseen R, et al. Improving the workflow efficiency of an outpatient pain clinic at a specialized oncology center by implementing lean principles. Asia Pac J Oncol Nurs 2019;6:381-8. 
34 Stein JD, Kapoor KG, Tootoo JL, et al. Access to ophthalmologists in states where optometrists have expanded scope of practice. JAMA Ophthalmol 2018;136:39-45.

35 Mahr MA, Erie JC. Comparing access to laser capsulotomy performed by optometrists and ophthalmologists in Oklahoma by calculated driving distance and time. Ophthalmology 2017:124:1290-5.

36 Lee CS, Morris A, Van Gelder RN, et al. Evaluating access to eye care in the contiguous United States by calculated driving time in the United States Medicare population. Ophthalmology 2016;123:2456-61
37 Zhang XJ, Liang YB, Liu YP, et al. Implementation of a free cataract surgery program in rural China: a community-based randomized interventional study. Ophthalmology 2013;120:260-5.

38 Jani PD, Forbes L, McDaniel P, et al. Geographic information systems mapping of diabetic retinopathy in an ocular telemedicine network. JAMA Ophthalmol 2017;135:715-21.

39 Xie W, Yang X, Cao X, et al. Effects of a comprehensive reservation service for non-emergency registration on appointment registration rate, patient waiting time, patient satisfaction and outpatient volume in a tertiary hospital in China. BMC Health Serv Res 2019;19:782 